\begin{tabular}{|l|l|l||}
\hline \multicolumn{2}{|c|}{ PublisherInfo } \\
\hline \hline PublisherName & $:$ & BioMed Central \\
\hline \hline PublisherLocation & $:$ & London \\
\hline \hline PublisherImprintName & $:$ & BioMed Central \\
\hline \hline
\end{tabular}

\title{
Anthrax toxin interactions
}

\begin{tabular}{|l|l|l||}
\hline \multicolumn{2}{|c|}{ ArticleInfo } \\
\hline \hline ArticleID & $:$ & 4364 \\
\hline \hline ArticleDOI & $:$ & $10.1186 /$ gb-2002-3-9-reports0050 \\
\hline \hline ArticleCitationID & $:$ & reports0050 \\
\hline \hline ArticleSequenceNumber & $:$ & 24 \\
\hline \hline ArticleCategory & $:$ & Paper report \\
\hline ArticleFirstPage & $:$ & 1 \\
\hline \hline ArticleLastPage & $:$ & 4 \\
\hline \hline & & RegistrationDate : 2002-6-28 \\
ArticleHistory & $:$ & Received \\
\hline ArticleCopyright & $:$ & BioMed Central Ltd2002 \\
\hline \hline ArticleGrants & $:$ & \\
\hline \hline
\end{tabular}




\begin{tabular}{|l|l|l||}
\hline ArticleContext & $:$ & 130593399 \\
\hline
\end{tabular}

Wim D'Haeze

\section{Summary}

Understanding how Bacillus anthracis initiates anthrax in humans

\section{Significance and context}

Bacillus anthracis is a large, Gram-positive, spore-forming rod bacterium with a size of approximately $1 \times 4 \mu \mathrm{m}$. It grows under both aerobic and anaerobic conditions and is related to $B$. cereus and $B$. thuringiensis. B. anthracis causes the disease called anthrax, which is primarily a disease of herbivorous animals such as cattle, horses, goats, and sheep. Humans can become infected when they have contact with diseased animals, including contact with bones, hair, and excrement. There are three types of anthrax: cutaneous (the most common), inhalation, and gastrointestinal. Cutaneous anthrax can lead to septicemia, and is the most common form of anthrax in humans; spores enter via a little wound or scratch on the skin. Inhalation anthrax occurs after inhalation of spore-containing dust and is often fatal if the invasive aspect of the infection cannot be stopped. Lastly, gastrointestinal anthrax is symptomatically similar to cutaneous anthrax but occurs in the intestinal mucosa.

The pathogenicity of $B$. anthracis is determined by two major components: a poly-D-glutamyl capsule and the anthrax toxin. The capsule, which is most important during the establishment of the disease, consists of a poly-D-glutamate polypeptide that gives virulent strains a smooth colony type and protects the bacterium against anti-microbial components of serum and against phagocytic engulfment. The anthrax toxin consists of three distinct antigenic components: protective antigen (PA), the edema factor $(\mathrm{EF})$, and the lethal factor (LF). EF is an adenylyl cyclase that causes edema when applied to animals in the presence of PA. LF is a zinc protease that cleaves particular mitogen-activated protein kinase kinases, and that (in combination with PA) causes death. Previously, it has been demonstrated that PA binds to an anthrax-toxin receptor. Receptor-bound PA is then cleaved into a $20 \mathrm{kDa}$ amino-terminal part (PA20) that is released, and a $63 \mathrm{kDa}$ carboxy-terminal part (PA63) that is bound to anthrax-toxin receptor. In contrast to whole PA, PA63 has the capacity to oligomerize and to form ring-shaped heptamers. These heptamers can bind up to three EF and/or LF molecules (ligand) and can be endocytosed. Internalized heptamers migrate to the endosomal compartments, where they are inserted into the membrane, forming a water-filled channel. Then, bound EF and/or LF molecules are delivered into the cytosol. The current work by Mogridge et al. demonstrates that PA63 oligomerization is required for ligand binding, and hence for the pathogenic effects of $B$. anthracis. 


\section{Key results}

In the first instance, two mutant PA63 proteins were constructed: one contained a D512K mutation and the other contained three mutations (K199E, R468A, and R470D). Both mutants were impaired in the capacity to form PA63 oligomers. When Chinese hamster ovary K1 cells were inoculated with either mutant PA63, no binding with LF could be observed. Upon inoculation of cells with an equimolar mixture of PA-D512K and PA- K199E/R468A/R470D, however, LF binding was observed, just as with wild-type PA63. This was confirmed by analysis of the electrophoretic mobilities of each mutant PA63, the wild-type PA63, and mixtures of both mutant PA63 proteins, in the presence of LF. The formation of a ternary complex in the latter case, consisting of a dimer of PA-D512K and PA- K199E/R468A/R470D bound to LF, was further demonstrated by means of size-exclusion column chromatography. These findings strongly suggest that PA63 oligomerization is required for LF binding. In addition, Mogridge et al. showed that, in the absence of ligand (EF or LF), only the PA63 heptamer, in which every subunit is bound to two neighboring subunits, is stable.

\section{Links}

The determination of the entire genome sequence of $B$. anthracis is currently under investigation and progress can be followed at the TIGR Microbial Database. More general information about $B$. anthracis and anthrax can be obtained from, for example, the Centers for Disease Control and Prevention Anthrax website. A related article appeared in the same edition of Proc Natl Acad Sci USA and described mapping of the site of key protein-protein interactions involved in anthrax initiation in humans (see related report - Genome Biology 3(9):reports0051).

\section{Reporter's comments}

B. anthracis is considered to be a severe human pathogen, and recently it has also become clear that this bacterium or its spores can be used in bioterrorist attacks. It is, therefore, of crucial importance to unravel all stages of anthrax infection and disease. The work by Mogridge et al. adds to our understanding of a particular step of the infection and will help provide a better picture of the disease, to serve as a basis for the development of new therapeutics and vaccines to rapidly battle established $B$. anthracis infection or to protect against infection.

\section{Table of links}


Proceedings of the National Academy of Sciences of the United States of America

TIGR Microbial Database

Centers for Disease Control and Prevention - Anthrax

Genome Biology 3(9):reports0051

\section{References}

1. Mogridge J, Cunningham K, Lacy DB, Mourez M, Collier RJ: The lethal and edema factors of anthrax toxin bind only to oligomeric forms of the protective antigen. Proc Natl Acad Sci USA. 2002, 99: 7045-7048. 